\title{
Experimental study on the preparation of BRA waterproof coating
}

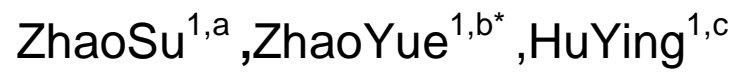 \\ ${ }^{1}$ Materials Science and Engineering,Shenyang Architectural University,ShenYang ,China \\ azhaosu2005@126.com,,1151936439@qq.com,,2515363294@qq.com
}

\begin{abstract}
Keywords: Buton rock asphalt,Waterproof coating,Modified asphalt,Fluorocarbon emulsion,Bentonite

Abstract. General petroleum asphalt is a common inexpensive impermeability of waterproof material, but its some performance limits its development. In order to make up for the defect and reduce the cost, we discussed the preparation of waterproof coating made of petroleum asphalt which is modified by BRA in this paper. We use the process of modification before emulsification to check the influences of dosage of BRA and bentonite, fluorocarbon emulsion on the properties of waterproof coating. The results prove that,this kind of waterproof coating has more excellent high temperature stability, elasticity,etc.The addition of bentonite can improve the plasticity,cohesiveness of waterproof coating. Fluorocarbon emulsion has a great influence on the low temperature properties of the waterproof coating.
\end{abstract}

\section{Introduction}

Petroleum asphalt,as the most widely used waterproof material in the waterproof anti-seepage engineering in domestic and international currently, is used for waterproof project with the advantages of the raw materials easy to get and low price ${ }^{[1]}$.

Kyminas et al. ${ }^{[2]}$ have made a relatively strong and durable roofing asphalt waterproof coating which is mainly used in roof waterproof eroded by the wind and rain in the long term.Roberts, etc ${ }^{[3]}$ have developed the asphalt waterproof coating used in the basement metope waterproof, which had a good weather resistance, chemical corrosion resistance, high tensile strength and high elongation.Construction science research institute of Shanxi province has developed environment-friendly water-based asphalt polyurethane waterproof coating ${ }^{[4]}$. They combined the oil asphalt and solid colored polyurethane waterproof coating, which keptthe good performance of waterproof coating and also reduced the cost.Jilin architecture and civil engineering institut ${ }^{[5]}$ studied the asphalt waterproof coating emulsified by bentonite, which was modified by fluorocarbon emulsion.It was found that the properties of crack resistance and low temperature flexibility of waterproof coating were improved.

However, some properties of petroleum asphalt, such as heat flow and cold brittleness, weather resistance and other problems, which hinders its application and development in the field of waterproof material. And the emergence of modified asphalt waterproof coating will overcome the problems of petroleum asphalt.Meanwhile, due to the enhancement of people's environmental consciousness, the research of modified asphalt has become a hot topic.

Buton rock asphalt(referred to as BRA) is a kind of natural asphalt produced on the Indonesian island of Buton ${ }^{[6]}$. Because of its perennial coexisting with environment and withstanding the long-term harsh test of environment in nature, its properties are particularly stable and have a strong weather resistance and "semi polymerization".It contains more impurities of clay and sand. Its asphalt content is about $20 \% \sim 30 \%$ and the rest is limestone mineral ${ }^{[7]}$. BRA, a kind of rarely cheaper and easyer to get modified material than petroleum asphalt, has a rich reserves and its mining is relatively simple.

Currently, our country applys BRA mainly to the construction of public transportation and road, but its application in research of waterproof coating has not been reported. Therefore, in this paper, it used BRA to modify asphalt and made bentonite and fluorocarbon emulsion as modification agent to prepare waterproof coating,after which we would evaluate its performance. 


\section{Experimental}

Raw materials. The A-90 asphalt(Liao river),Buton rock asphalt(Indonesian island of Buton),Fluorocarbon resin emulsion(Changshu run Lin fluorine and silicone material Co., Ltd,solid content, $\geq 45 \%$ ), Bentonite(Shenzhen Haiyang Powder Technology Co., Ltd,containings of montmorillonite, $\geq 85 \%$ ), Styrene butadiene latex(Jiangsu dongtai citizens kay chemical co., Ltd,solid content, $\geq 20 \%$ ), Chloroprene latex(Shanghai chemical technology Co., Ltd, solid content, $\geq 48 \%$ ).

Experimental Procedure. 1)According to take adequate amount of the matrix asphalt, heated to $160-200{ }^{\circ} \mathrm{C}$. Then add dosage of $20 \%$ BRA and stir for $30 \mathrm{~min}$ in $180{ }^{\circ} \mathrm{C}$. The samples will be put in oven 20 min, a quick modified asphalt gotten. 2) According to take a certain amount of the organobentonite,adding appropriate $70^{\circ} \mathrm{C}$ hot water. After mixing evenly, put it into the oven for $8 \mathrm{~h}$. Then the bentonite paste is made. 3)The modified asphalt was heated to $160-200^{\circ} \mathrm{C}$. Add $12 \%$ content of organobentonite and stir $30 \mathrm{~min}$ in $180{ }^{\circ} \mathrm{C}$. Then the emulsified asphalt is prepared. 4)It is cooled to $50{ }^{\circ} \mathrm{C}$, adding $10 \%$ content of fluorocarbon emulsion. Make it mixed with emulsified asphalt evenly. Then cooling to $40{ }^{\circ} \mathrm{C}$,BRA modified asphalt waterproof coating is made.

Performance test. Test method for specified performance of BRA modified asphalt waterproof coating was according to JC/T408-2005 emulsion waterproof coating .

\section{Results and analysis}

The influence of dosage of BRA. In the case of constant temperature and stirring rate,study its effect on the basic properties of the matrix asphalt by changing the content of BRA.The experimental results are shown in Table 1.

Table 1 Effect of the content of BRA on matrix asphalt

\begin{tabular}{cccccc}
\hline Serial number & BRA content $(\%)$ & Needle & penetration & Softening point $\left({ }^{\circ} \mathrm{C}\right)$ & Ductility $(\mathrm{cm})$ \\
\hline 1 & 0 & 92.4 & 45.9 & 168.9 \\
2 & 5 & 86 & 46.7 & 166.7 \\
3 & 15 & 80.9 & 50.2 & 164.2 \\
4 & 20 & 75 & 53.4 & 160.3 \\
5 & 25 & 72.8 & 59.1 & 155.6 \\
6 & 30 & 70 & 61.8 & 147.4 \\
7 & 35 & 68 & 68.6 & 144.8 \\
8 & 40 & 67.2 & 75.5 & 140.3 \\
\hline
\end{tabular}

Notes: The penetration $\left(25^{\circ} \mathrm{C} 100 \mathrm{~g}, 5 \mathrm{~S}, 0.1 \mathrm{~mm}\right)$, ductility $(15 \mathrm{C}, 5 \mathrm{~cm} / \mathrm{min})$.

From Table 1,it can be concluded that asphalt penetration decreases along with the addition of BRA. When dosage of bra is in more than $20 \%$, penetration do not significantly change. Asphalt asphalt penetration show soft and hard degree and consistency and the resistance to shear failure, which reflect the index of relative viscosity of asphalt in certain condition.It suggests that the addition of BRA improves the structure of asphalt for increasing the hardness and reducing consistency.The addition of BRA will also change the softening point of asphalt. Along with the augment of BRA, softening point increases, while the BRA content continues to grow to $25 \%$, the softening point changes rarely.And with the augment of BRA, asphalt ductility decreases, but not so much.Asphalt softening point and ductility respectively reflect the thermal stability and low temperature extension of asphalt.Hence,the datas in Table 1 suggests that BRA effectively improves the high temperature property of matrix asphalt, and at the same time,reduces the low temperature performance, but only to a small extent.Therefore,through comprehensive analysis, the effect of modified asphalt is better when BRA content is $20 \%$.

Make microanalysis of $20 \%$ content of the BRA and the minerals in BRA with the S-4800 ice emission scanning electron microscope and test results is shown in Figure 1, 2. 


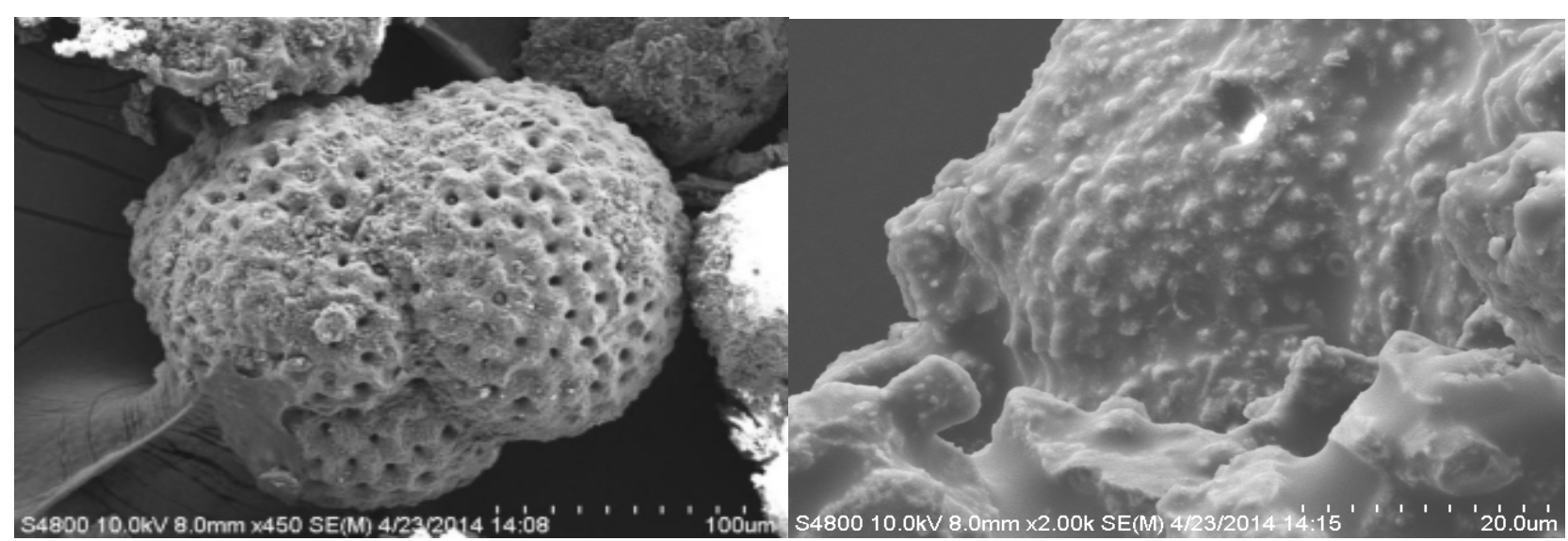

Figure 1 the diagram of powders of BRA in SEM (left),figure 2 the diagram of $20 \%$ BRA in SEM (right)

Figure 1 shows that BRA has developed pores in the mineralpowder, some of which deep into the interior of the mineral.Mineral surface is rough, uneven and higher crystallization degree. This shows that the properties of BRA are stable and it has strong adhesion. Through the Figure 2, it is observed that BRA and asphalt are mutually inclusive and particle surface coats with asphalt that permeates in the slag particles in the asphalt mixture, which forming a kind of continuous overlapping two-phase structure $^{[8]}$.This structure shape makes modified asphalt by BRA good heat storage stability and rheological property.Therefore, thermal stability, elasticity and film-forming property of BRA modified asphalt waterproof coating will be improved greatly.

BRA modification is just a simple physical mixing processes through the Figure 1 and Figure 2 and the "half aggregation effect" of BRA formes many active areas which can combine with the matrix asphalt quickly to form a continuous overlapping two-phase structure.This formation makes softening point rise rapidly,reduces the hardness of asphalt,increases its creep performance and lowers its properties of cracking tensile in the low temperature.It illustrates that BRA can improve the high temperature performance of matrix asphalt greatly with reducing its performance at low temperature. And fluorocarbon emulsion can modify the low temperature performance of waterproof coating, which makes up for the deficiency. The combination of both improves high temperature stability, low temperature flexibility and frost resistance of waterproof coating effectively.

The influence of the emulsifier. Select of bentonite,styrene butadiene latex and chloroprene latex as emulsifier.Make comparison experiment and record the effect of modification. The results are shown in Table 2.

Table 2 Effect of emulsifier on modified asphalt by BRA

\begin{tabular}{|c|c|c|c|c|c|}
\hline Emulsifier & Heat resistance & $\begin{array}{l}\text { Iimpervious } \\
\text { property }\end{array}$ & $\begin{array}{l}\text { Surface drying } \\
\text { time(h) }\end{array}$ & $\begin{array}{c}\text { Low } \\
\text { temperature } \\
\text { flexibility }\end{array}$ & Apparent state \\
\hline $\begin{array}{l}\text { No modifier } \\
\text { agent }\end{array}$ & drippage & seepage & 2 & preferably & $\begin{array}{c}\text { black, solid at room } \\
\text { temperature }\end{array}$ \\
\hline Bentonite & no flow & non seepage & 6 & preferably & $\begin{array}{c}\text { puce,pasty at room } \\
\text { temperature }\end{array}$ \\
\hline $\begin{array}{c}\text { Styrene } \\
\text { butadiene latex }\end{array}$ & $\begin{array}{l}\text { flowing without } \\
\text { dripping }\end{array}$ & non seepage & 8 & preferably & $\begin{array}{c}\text { black, pasty at room } \\
\text { temperature }\end{array}$ \\
\hline Neoprene latex & $\begin{array}{l}\text { flowing without } \\
\text { dripping }\end{array}$ & non seepage & 8 & poor & $\begin{array}{l}\text { brown,pasty at } \\
\text { room temperature }\end{array}$ \\
\hline
\end{tabular}

Notes:impervious property (200mm water static pressure for 7D),low temperature flexibility $\left(-15^{\circ} \mathrm{C}\right)$

It can be drawn by Table 2 that bentonite, styrene butadiene latex and chloroprene latex all have good effects to emulsify the modified asphalt by BRA.After the addition of emulsifier, modified 
asphalt by BRA looks like a paste or liquid at room temperature with a good heat resistance and waterproof impermeability.But the emulsifications of styrene butadiene latex or chloroprene latex decrease its heat resistance with waterproof coating flowing under the standard test condition.Especially the low temperature property of chloroprene latex is also very poor, it can be observed obvious cracks with the naked eye in testing standards .

Bentonite crystal structure unit is composed of two layers of $\mathrm{SiO}_{4}$ tetrahedron and a layer of $\mathrm{AlO}_{2}(\mathrm{OH})_{4}$ octahedron among them ${ }^{[9]}$.Its cations in the interlayer are easy to be exchanged,which makes it a great deal of ion exchange capacity. The isomorphism exchange in this structure causes the unit cell remaining negative charge, which becomes the root cause of emerging interlayer water in structure.And c axis also expands with increase of the amount of water,which renders bentonite a good expansibility,adsorption and cation exchange to provide a favorable condition of composite or insertion reaction for the object matter. And modified sodium base bentonite has more superior physical and chemical properties, such as greater bibulous rater,higher expansion ratio and bigger cation exchange capacity and its colloidal suspension possesses good thixotropy,viscosity,lubricity,thermal stability,plasticity and cohesiveness ${ }^{[10]}$.Consequently, it can widely improve various performance indexes of the waterproof coating and lower cost by choosing sodium base bentonite as emulsifier.

The effect of fluorocarbon emulsion. Choose fluorocarbon emulsion as a modifier for experiment and record its modification effects. The results are shown in Table 3.

Table 3 Comparison of the performance of the modified waterproof coating by fluorocarbon emulsion

\begin{tabular}{ccc}
\hline Project & Before modification & After modification \\
\hline Flexibilit $(\Phi 10 \mathrm{~mm})$ & $(-12 \pm 1)^{\circ}$ Cno crack, fracture & $(-19 \pm 1)^{\circ} \mathrm{Cno}$ crack, fracture \\
Heat resistance & $120^{\circ}$ Cno flow, foaming and sliding & $180^{\circ}$ Cno flow, foaming and sliding \\
Elongation at break $(\%)$ & 1.20 & 1.50 \\
Water impermeability $(0.1$ & non seepage & non seepage \\
MPa, 30min) & no cracking of fifteen times & no cracking of twenty times \\
Freezing resistance & 200 & 1600 \\
Artificial accelerated aging(h) & $0.25($ film thickness of $2.3 \mathrm{~mm})$ & $0.3($ film thickness of $1.0 \mathrm{~mm})$ \\
Anti-permeability (MPa) & &
\end{tabular}

According to the results of the Table 3, it shows that the properties of waterproof coating,such as waterproofness,artificial aging resistance,elongation at break and flexibility, are improved significantly after using fluorocarbon emulsion. And this is because the fluorocarbon polymer molecules exists the $\mathrm{C}-\mathrm{F}$ key,greater than $\mathrm{C}-\mathrm{H}$ key and the shielding effect of electron clouds of the fluorine atoms to $\mathrm{C}-\mathrm{C}$ key is stronger than $\mathrm{H}$ atoms. Therefore, fluorine atoms can protect it from uv and chemical substances, which improves the artificial aging resistance of waterproof coating to a great extent.Also because of its unique polarity, $\mathrm{F}$ atoms form electrostatic protective layer in the molecule periphery,excluding other polar molecules, which shows the special surface properties of fluorocarbon coating, such as contamination resistance,self-cleaning, low frictional,repelling water and oil and electrical insulation and greatly improves its compatibility with other substances ${ }^{[11]}$. This experiment adopts the average particle size of fluorocarbon emulsion at about $200 \mathrm{~nm}$ for the good compatibility with bentonite emulsified asphalt, which not only improves the stability of emulsified asphalt,but also ensures to form a dense protective film between the emulsion particles and emulsion asphalt.It can effectively prevent erosion of the film and also improve the impermeability of waterproof coating,so that waterproof coating will have more excellent mechanical properties.

The addition of fluorocarbon emulsion can improve the performances of waterproof coating and the amount of that has different influences on its performance.The polymer can not be formed stable and elastic protective layer inside of coating, if too little. As well, if in excess, coating internal system is 
easy to occur phase transformation, the discontinuous phase polymer becoming continuous phase and the asphalt turned into the continuous phase.Moreover,it can increase the cost if fluorocarbon emulsion dosage is too high.So the content of that is controlled at about $10 \%$. And choose the good low-temperature film-forming fluorocarbon emulsion (which has good elongation at break and elongation rate of springback), to improve low temperature flexibility, elongation and elasticity of the emulsified asphalt effectively.

\section{Conclusions}

1. BRA, as a modifier of matrix asphalt,improves the softening point, needle penetration and ductility obviously and also advances the thermal stability,elasticity and film-forming properties of waterproof coating greatly. It's determined experimentally that $20 \%$ mixing amount of BRA has better modification.

2. Bentonite as emulsifier can improve the thermal stability of the waterproof coating better.

3. Fluorocarbon emulsion and BRA can make up for the deficiency of each other, which improves the properties of waterproof coating,such as anti-permeability,film-formation,low temperature flexibility and durability obviously.It's determined experimentally that $10 \%$ mixing amount of fluorocarbon emulsion has better modification.

4. BRA is more cheap and easy to get than asphalt and the substitution amount of BRA is up to $20 \%$ in the experiment,which greatly saves the cost, in favour of mass production,popularization and application.

\section{References}

[1] Shuxiang Zhang ,Bingyong Han et al.,J.Shandong Building Materials College Journal, 11 (1997) 50-54. (In Chinese)

[2] Kyminas Stanley C Phillips,et al.:U.S. Patent 4,859,723. (1989).

[3] RobertsMichel G:U.S. Patent 5,804,635.(1998) .

[4] Fangfang Wang, J. Chemical Building Materials, (2002) 2, 43-44. (In Chinese)

[5] Gao Tong, Xu Chao, J. New Building Materials, 10 (2005) :59-60. (In Chinese)

[6] Wang Wei, Modified asphalt by BRA and its mixture properties [D]. Changsha:Changsha University of Science and Technology,2008. (In Chinese)

[7] Zhigang Ye ,Xianming Kong ,Jianying Yu , Lianqi Wei, J. Journal of Wuhan University of Technology-Mater. Sci. Ed., 18 (2003) 1, 83-85.

[8] Ruixia Li, J.Technology of Highway and Transport, 28 (2011) 12, 2-3. (In Chinese)

[9] Lihong Zhao, Wenxia Liu,J.Chinese Paper Making, 23 (2004) 10, 49-53. (In Chinese)

[10] Hongqing Han,J. Inorganic Salt Industry, 43 (2011) 10, 2-5. (In Chinese)

[11] Youpeng Wang, Xiaorong He ,J. New Building Materials, 03 (2009) 66-68. (In Chinese) 